\title{
Validated analytical study of the effect of Lycopene on the pharmacokinetics of Paracetamol and Chlorzoxazone in rats
}

\author{
Reem Baha-Aldeen Youssef ${ }^{1}$, Marwa Ahmed Fouad*,1, Asmaa Ahmed El-Zaher ${ }^{1}$
}

${ }^{1}$ Pharmaceutical Chemistry Department, Faculty of Pharmacy, Cairo University, Egypt

\begin{abstract}
Lycopene was reported to influence some cytochrome P450 enzymes activity. The present study investigates the effect of lycopene on the pharmacokinetics of paracetamol and chlorzoxazone. Lycopene $(20 \mathrm{mg} / \mathrm{kg})$ was intra-peritoneally administered to two groups of rats for eight consecutive days and two other groups were given vehicle. On the eighth day, chlorzoxazone and paracetamol were separately intravenously administered to a lycopene group and a control group. Blood samples were collected at different time intervals, treated and analyzed using HPLC. The HPLC method used for paracetamol analysis was based on isocratic elution using a mobile phase consisting of water: methanol, (77:23 v/v) at a flow rate $1 \mathrm{~mL} \mathrm{~min}{ }^{-1}$, Kromasil $\mathrm{C} 18$ column, and UV detection at $254 \mathrm{~nm}$ using caffeine as internal standard. About chlorzoxazone, separation was carried out using water: acetonitrile (60: 40, v/v) as the mobile phase at a flow rate $1 \mathrm{~mL} \mathrm{~min}{ }^{-1}$, Inertsil ODS-3 C18 column, UV detection at $283 \mathrm{~nm}$ and esomeprazole as internal standard. Statistical analysis of the pharmacokinetic data using student $\mathrm{t}$ test showed a significant increase in $A U C_{0-t}, A U C_{0-\text { Inf }}$ and $t 1 / 2$ of paracetamol $(\mathrm{P}<0.05)$ and of chlorzoxazone $(\mathrm{P}<0.05)$ in the groups pretreated with lycopene $(20 \mathrm{mg} / \mathrm{kg})$, significant increase in the volume of distribution of paracetamol $(\mathrm{P}<0.05)$, but no significant difference in that of chlorzoxazone. In other words, paracetamol and chlorzoxazone showed significant decrease $(\mathrm{P}<0.05)$, respectively. These results demonstrate that treatment of rats with Lycopene $(20 \mathrm{mg} / \mathrm{kg}$, ip) has a significant effect on the metabolic clearance and the pharmacokinetics of both drugs.
\end{abstract}

Keywords: Lycopene/ chemistry. Paracetamol/pharmacokinetics. Chlorzoxazone/pharmacokinetics. Acetaminophen/pharmacokinetics. AUC. Area under curve. Volume of distribution. Validation studies. Metabolic clearance rate/drug effects. HPLC/methods. Chromatography. High Pressure Liquid/methods. Rats/metabolism.

\section{INTRODUCTION}

Lycopene is a non provitamin A carotenoid, concentrated in tomatoes and other red fruits (Schulzová, Hajšlová, 2007). Great interest to lycopene was recently observed because most studies proved that those who consume more lycopene and accordingly have high concentrations in plasma have lower incidence for chronic illness such as cancer and coronary heart diseases (Gerster, 1997; Rao, Agarwal, 1999). More studies proved the effect of lycopene to decrease bone resorption and thus improve osteoporosis (MacKinnon et al., 2011).

In a previous study, Tomato juice showed a potent inhibitory effect on nifedipine oxidation activity, which was comparable to that on testosterone $6 \beta$-hydroxylation

\footnotetext{
*Correspondence: M. A. Fouad. Pharmaceutical Chemistry Department, Faculty of Pharmacy, Cairo University, Kasr Eleini street, Cairo, Egypt. Tel: +201222441198. E-mail: marwa.fouad@pharma.cu.edu.eg (D)
}

activity, and weak inhibitory effect on midazolam 1 '-hydroxylation activity ,by one or more mechanismbased and competitive inhibitor(s) of CYP3A4 (Sunaga et al., 2012).

Hence, the carotenoid lycopene is increasingly gaining scientific attention because of its potential health effects. However, little is known about the metabolic interactions between lycopene and clinically used drugs like paracetamol and chlorzoxazone.

Paracetamol (acetaminophen, $N$-acetyl- $p$ aminophenol, PAR) is one of the most popular and widely used drugs for the treatment of pain and fever. Due to its good tolerability profile, PAR is often the analgesic or antipyretic of choice, especially in patients in whom salicylates or other non-steroidal anti-inflammatory drugs are contraindicated (Portolés et al., 2003; Wang et al., 2018).

Cytochrome P450 enzymes, CYP2E1 and CYP1A2, catalyze oxidation of PAR to the reactive metabolite 
$\mathrm{N}$-acetyl-p-benzoquinone imine (NAPQI) (McGill, Jaeschke, 2013). Numerous drugs have been reported to interact with PAR leading to exacerbation of its toxicity, so PAR should be administered carefully to people on isoniazid treatment or consuming excessive amounts of alcohol to prevent hepatotoxicity due to the induction of CYP2E1. PAR toxicity can occur when CYP2E1 metabolism is impaired by drug-drug interactions (Zand et al., 1993).

Chlorzoxazone (5-chloro-2(3H)-benzoxazolone; CZX), a skeletal muscle relaxant used for the treatment of painful muscle spasms is primarily metabolized to 6-hydroxychlorzoxazone (OH-CZX), which is subsequently glucuronidated and excreted in the urine (Kar, 2005; Kramer et al., 2003). Hepatic microsomal cytochrome P450 enzyme (CYP2E1) plays an important role in the formation of $\mathrm{OH}-\mathrm{CZX}$ from $\mathrm{CZX}$ in humans and rats (Rockich, Blouin, 1999; Peter et al., 1990). Previous studies showed that lycopene has the ability to inhibit CYP2E1 in the rat microsomal model (Louisa et $a l ., 2009)$. So far, there has been no information about the effects of Lycopene on the pharmacokinetics of CZX and PAR. The aim of this study was to determine this influence in rats using bioanalytical HPLC method.

\section{MATERIAL AND METHODS}

\section{Chemicals and solvents}

Lycopene extract was kindly supplied from UG PHARMA company, Badr City, Egypt. Paracetamol, chlorzoxazone, esomeprazole and caffeine were kindly supplied from Memphis Company, Cairo, Egypt. Heparin (Calheparin 5000UI AMP) was purchased from Amoun Pharmaceutical Industries Company, Kaliobeya, Egypt). Methanol for HPLC and ethyl acetate were purchased from Sigma-Aldrich, Munich, Germany. Bi-distilled water was produced in-house (Aquatron Water Still, A4000D, UK).

\section{Instrumentation}

A chromatographic system (Younglin instrument Acme 9000, Korea) equipped with vacuum degasser, mixer, gradient pump and UV/VIS detector was used. Separation and quantitation were made on Kromasil ${ }^{\circledR}$ C18 column (150 x $4.6 \mathrm{~mm}, 5 \mu \mathrm{m})$, Agilent, USA and Inertsil ODS-3:C18 column ( $250 \times 4.6 \mathrm{~mm}, 5 \mu \mathrm{m})$, Japan. Magnetic stirrer model Labinco L33, Fronteir ${ }^{\mathrm{TM}}$ Centrifuge FC5706, OHAUS, Germany and Ultrasonic processor; Soniclean 120T, Barton SA, Australia were used.

\section{Lycopene stock solution}

Lycopene extract $10 \%$ equivalent to $200 \mathrm{mg}$ was dissolved in $10 \mathrm{~mL}$ water to obtain a final concentration $20 \mathrm{mg} / \mathrm{mL}$ of pure lycopene.

\section{Animal experiment}

24 Male Wister rats, 250-450 g, obtained from the Laboratory Animal Center, Faculty of Pharmacy, Cairo University, were housed, six rats per cage, and given free access to food and water in a temperature-controlled room $\left(25^{\circ} \mathrm{C}\right)$ with a $12 \mathrm{~h}$ light/dark cycle. The study protocol was reviewed and approved (PC (1687) on $26^{\text {th }}$ April 2016 by the Institutional Review Board (REC-FOPCU; Research Ethics Committee-Faculty of Pharmacy, Cairo University) in Egypt. All applicable international, national, and/or institutional guidelines for the care and use of animals were followed. The rats were randomLy divided into four groups: (1) Lycopene group of PAR (pretreated with lycopene (20 mg/kg, n=6) (2) Control group of PAR (pretreated with vehicle (water for injection), $n=6$ ) (3) Lycopene group of CZX (pretreated with lycopene (20 mg/kg), n=6) (4) Control group of CZX pretreated with vehicle (normal saline), $n=6$ ).

All the rats were given vehicle (control group) or lycopene (lycopene group) intraperitoneally on a daily basis for 8 consecutive days. On the eighth day, access to the diet was removed and only water was provided. After treatment with water or lycopene, PAR $(25 \mathrm{mg} / \mathrm{kg})$ was given to group (1) and group (2) and CZX (20 mg/kg) was given to group (3) and group (4) by intravenous administration in the tail.

After administration of PAR and CZX, $300 \mu \mathrm{Lblood}$ samples were collected from the vein of the eye at different time intervals $(0,0.25,0.5,1,2,4,6 \mathrm{hr})$. The plasma samples were separated via Eppendorf containing $50 \mu \mathrm{L}$ of diluted heparin (1:10) by centrifugation at $4,000 \mathrm{rpm}$ for $15 \mathrm{~min}$ and stored at $-20^{\circ} \mathrm{C}$ until analysis.

\section{Extraction method of PAR}

A liquid-liquid extraction method was used for extraction of PAR from plasma matrix. In an Eppendorf, an aliquot of $20 \mu \mathrm{L}$ internal standard stock solution (Caffeine $400 \mu \mathrm{g} / \mathrm{mL}$ ) and $60 \mu \mathrm{L}$ water were added to $120 \mu \mathrm{L}$ plasma samples taken from groups (1) and (2) and then $1000 \mu \mathrm{L}$ of a mixture of methanol and ethyl acetate (1:9) was added. The solution was vortexed for $30 \mathrm{~s}$ and the supernatant was separated by centrifugation at $4,000 \mathrm{rpm}$ for $10 \mathrm{~min}$. The organic layer was separated and evaporated to dryness at 
$40{ }^{\circ} \mathrm{C}$ under a gentle stream of nitrogen. The residue was reconstituted in $100 \mu \mathrm{L}$ mixture of methanol and water (77: 23), then $20 \mu \mathrm{L}$ was injected onto HPLC. The final concentration of IS is $80 \mu \mathrm{g} / \mathrm{mL}$.

\section{Extraction method of CZX}

A protein precipitation method was used for extraction of CZX from plasma matrix. An aliquot of $20 \mu \mathrm{L}$ internal standard stock solution (Esomeprazole, $880 \mu \mathrm{g} / \mathrm{mL}$ ) and $60 \mu \mathrm{L}$ water were added to $120 \mu \mathrm{L}$ plasma samples taken from groups (3) and (4) in Eppendorf and then $200 \mu \mathrm{L}$ of a mixture of water and acetonitrile (4:6) was added. The solution was vortexed for $30 \mathrm{~s}$ and the supernatant was separated by centrifugation at $6,000 \mathrm{rpm}$ for $15 \mathrm{~min}$, then $20 \mu \mathrm{L}$ was injected onto HPLC. The final concentration of IS is $44 \mu \mathrm{g} / \mathrm{mL}$.

\section{Assay of PAR in rat plasma}

PAR plasma concentration was determined using HPLC. Chromatographic separation was achieved on a Kromasil C18 column ( 150 X $4.6 \mathrm{~mm}, 5 \mu \mathrm{m})$ using a mobile phase consisting of water: methanol $(77: 23, \mathrm{v} / \mathrm{v})$ at a flow rate $1 \mathrm{~mL} \mathrm{~min}{ }^{-1}$. The column temperature was $25^{\circ} \mathrm{C}$. UV detector was operated at $254 \mathrm{~nm}$. The injection volume was $20 \mu \mathrm{L}$.

\section{Assay of CZX in rat plasma}

Chromatographic separation of CZX plasma concentration was achieved on an Inertsil C18 column $(250 \times 4.6 \mathrm{~mm}, 5 \mu \mathrm{m})$ using a mobile phase consisting of

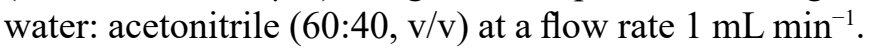
The column temperature was $25^{\circ} \mathrm{C}$. UV detector was operated at $283 \mathrm{~nm}$. The injection volume was $20 \mu \mathrm{L}$.

\section{Bioanalytical method validation (EMA, 2015)}

\section{Preparation of Calibration standards and quality control samples}

Stock solutions of PAR $\left(2.5-200 \mu \mathrm{g} \mathrm{mL}^{-1}\right)$ were diluted in water to get concentrations of calibration curve $\left(0.5-40 \mu \mathrm{g} \mathrm{mL}^{-1}\right)$. Stock solutions of PAR (2.5, $\left.7.5,100,150 \mu \mathrm{g} \mathrm{mL}^{-1}\right)$ were diluted in water to get quality control samples $(\mathrm{LLOQ}=0.5$, Low $=1.5$, Med $=20$, High $\left.=30 \mu \mathrm{g} \mathrm{mL}^{-1}\right)$. Stock solution of caffeine (400 $\left.\mu \mathrm{g} \mathrm{mL}^{-1}\right)$ was diluted in distilled water to get concentration $\left(80 \mu \mathrm{g} \mathrm{mL}^{-1}\right)$ (IS). A $100 \mu \mathrm{L}$ aliquot of rat plasma was spiked with $20 \mu \mathrm{L}$ of stock solution, $20 \mu \mathrm{L}$ of Caffeine stock solution (IS) and $60 \mu \mathrm{L}$ water. To $200 \mu \mathrm{L}$ of the spiked calibration plasma standards or QC samples, $1000 \mu \mathrm{L}$ mixture of ethyl acetate and methanol (9:1) was added and the extraction procedure was continued as mentioned in "Extraction method of PAR".

Stock solutions of CZX (10-800 $\left.\mu \mathrm{g} \mathrm{mL}^{-1}\right)$ were diluted in acetonitrile to get concentrations of calibration curve $\left(0.5-40 \mu \mathrm{g} \mathrm{mL}^{-1}\right)$. Stock solutions of CZX $(10,30$, $\left.400,600 \mu \mathrm{g} \mathrm{mL}^{-1}\right)$ were diluted in acetonitrile to get quality control samples $(\mathrm{LLOQ}=0.5, \mathrm{Low}=1.5, \mathrm{Med}=20$, High $\left.=30 \mu \mathrm{g} \mathrm{mL}^{-1}\right)$. Stock solution of Esomeprazole $\left(880 \mu \mathrm{g} \mathrm{mL}^{-1}\right)$ was diluted in distilled water to get concentration ( $44 \mu \mathrm{g} \mathrm{mL}^{-1}$ ) (IS). A $100 \mu \mathrm{L}$ aliquot of rat's plasma was spiked with $20 \mu \mathrm{L}$ of stock solution, $20 \mu \mathrm{L}$ of Esomeprazole stock solution (IS) and $60 \mu \mathrm{L}$ water. To $200 \mu \mathrm{L}$ of the spiked calibration plasma standards or QC samples, $200 \mu \mathrm{L}$ mixture of acetonitrile and water $(6: 4)$ was added and the extraction procedure was continued as mentioned in "Extraction method of CZX".

Calibration curves were constructed by plotting peak area ratio of the drug to IS versus the corresponding drug concentration in both PAR and CZX. The constructed calibration curves were found to be linear and precise for PAR and CZX over the linearity range of 0.5 $40 \mu \mathrm{g} \mathrm{mL}^{-1}$. The regression equations were also computed $\left(\mathrm{Y}=0.0287 \mathrm{x}+0.0013, \mathrm{R}^{2}=0.9998\right)$ for $\mathrm{CZX}$ and $\left(Y=0.0448 x+0.0099, R^{2}=0.998\right)$ for PAR.

\section{Selectivity}

Selectivity was checked by using 6 randomLy selected drug-free rats' plasma, (processed by the protein precipitation extraction procedure for CZX or liquid-liquid extraction for PAR) which was analyzed to determine the extent to which endogenous plasma components may contribute to the interference at the retention time of analytes and IS. There was no significant interference at the retention times of both CZX, PAR or IS from the six different batches of drug-free rat plasma used for analysis, as shown in Figures 2 and 3.

\section{Carry-over}

Carry-over was assessed by injecting blank samples after a high concentration sample $\left(30 \mu \mathrm{g} \mathrm{mL}^{-1}\right)$ of both PAR and CZX. Carry over in the blank sample did not exceed $20 \%$ of the lower limit of quantification and $5 \%$ for the internal standard.

\section{Accuracy and precision (inter and intra-day)}

For the evaluation of precision, the deviation of each concentration level from the nominal concentration should to be within $\pm 15.0 \%$. Similarly, the mean accuracy should not deviate by $\pm 15.0 \%$ of the nominal 


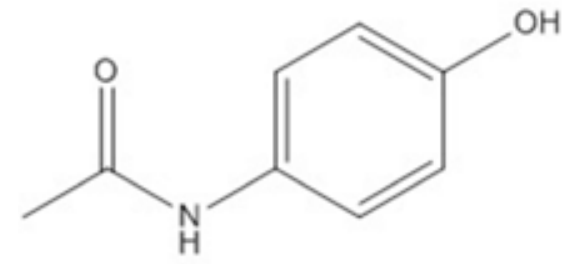

(a)

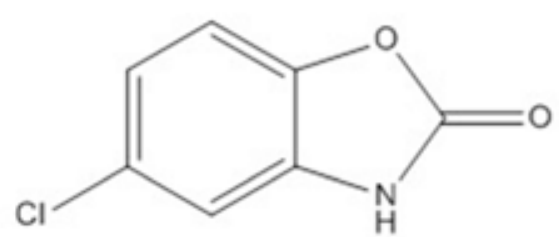

(b)

FIGURE 1 - Chemical structure of (a) paracetamol, (b) chlorzoxazone.
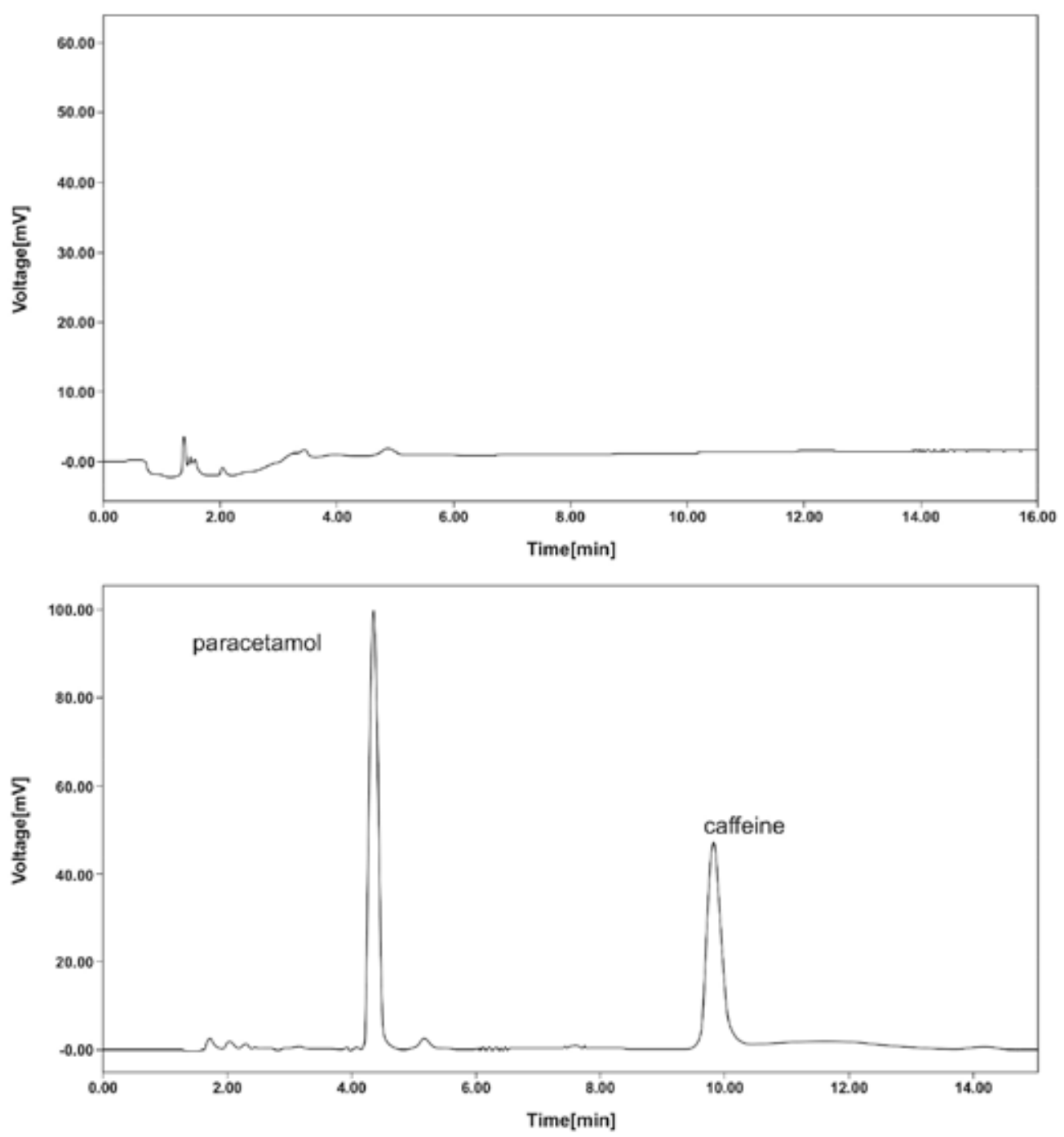

FIGURE 2 - Chromatogram of (a) blank rat's plasma (b) Rat plasma spiked with paracetamol (30 $\mu \mathrm{g} / \mathrm{mL})$ and caffeine $(80 \mu \mathrm{g} / \mathrm{mL})$.

concentration except for the LLOQ which should be within $20 \%$ of the nominal value. The results are presented in Tables I and II.

\section{Stability}

To evaluate the stability of both PAR and CZX under different storage conditions, three aliquots of each low and high QC samples were stored in a deep freezer at $-80 \pm$
$2{ }^{\circ} \mathrm{C}$ for two weeks. After two weeks, the samples were processed along with precision and accuracy batches. Concentrations obtained were compared with nominal concentrations to determine the long-term stability of both PAR and CZX in rat plasma.

The short-term stability was determined by keeping three aliquots of unprocessed QC samples at ambient temperature for $6.0 \mathrm{~h}$. After $6.0 \mathrm{~h}$, the samples 

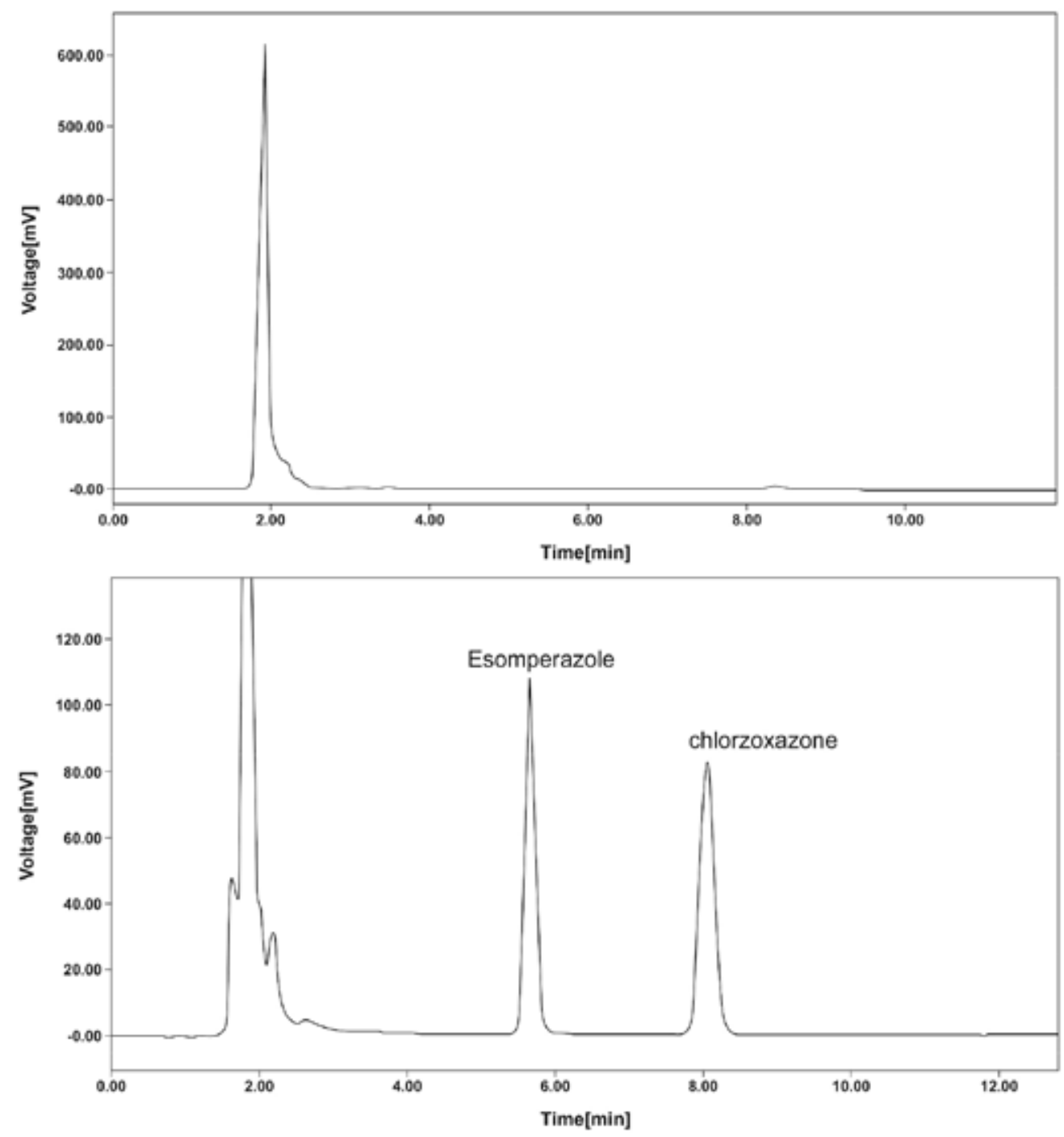

FIGURE 3 - Chromatogram of (a) blank rat's plasma (b) Rat plasma spiked with chlorzoxazone $(30 \mu \mathrm{g} / \mathrm{mL})$ and esomeprazole $(44 \mu \mathrm{g} / \mathrm{mL})$.

TABLE I - The results of Intra- and Inter-day accuracy and precision for the determination of paracetamol in rat plasma

\begin{tabular}{lcccccc}
\hline $\begin{array}{l}\text { Accuracy and } \\
\text { Precision }\end{array}$ & QC samples & $\begin{array}{c}\text { Concentration } \\
\text { of PAR }(\boldsymbol{\mu g} / \mathbf{m L}) \\
\text { in rat plasma }\end{array}$ & $\begin{array}{c}\text { Mean Found } \\
\text { Concentration } \\
(\boldsymbol{\mu g} / \mathbf{m L}) \text { of PAR }\end{array}$ & \pm SD & CV & Recovery \% \\
\hline \multirow{4}{*}{ Intraday } & LLOQ & 0.5 & 0.473 & 0.066 & 13.953 & 94.600 \\
& Low & 1.5 & 1.490 & 0.099 & 6.644 & 99.333 \\
& Medium & 20 & 19.950 & 0.426 & 2.135 & 99.750 \\
\hline \multirow{3}{*}{ Interday } & High & 30 & 28.707 & 1.398 & 4.869 & 95.690 \\
& LLOQ & 0.5 & 0.500 & 0.049 & 9.800 & 100.000 \\
& Low & 1.5 & 1.429 & 0.089 & 6.228 & 95.266 \\
& Medium & 20 & 18.840 & 0.722 & 3.832 & 94.200 \\
\hline
\end{tabular}


TABLE II - The results of intra- and inter-day accuracy and precision for the determination of chlorzoxazone in rat plasma

\begin{tabular}{|c|c|c|c|c|c|c|}
\hline $\begin{array}{l}\text { Accuracy and } \\
\text { Precision }\end{array}$ & QC samples & $\begin{array}{c}\text { Concentration of } \\
\mathrm{CZX}(\mu \mathrm{g} / \mathrm{mL}) \\
\text { in rat plasma }\end{array}$ & $\begin{array}{c}\text { Mean Found } \\
\text { Concentration } \\
(\mu \mathrm{g} / \mathrm{mL}) \text { of } \mathrm{CZX} \\
\end{array}$ & \pm SD & $\mathrm{CV}$ & Recovery \% \\
\hline \multirow{4}{*}{ Intraday } & LLOQ & 0.5 & 0.525 & 0.040 & 7.619 & 105.000 \\
\hline & Low & 1.5 & 1.560 & 0.152 & 9.744 & 104.000 \\
\hline & Medium & 20 & 20.981 & 1.634 & 7.869 & 104.905 \\
\hline & High & 30 & 30.765 & 1.177 & 3.826 & 102.550 \\
\hline \multirow{4}{*}{ Interday } & LLOQ & 0.5 & 0.538 & 0.007 & 1.301 & 107.600 \\
\hline & Low & 1.5 & 1.503 & 0.114 & 7.585 & 100.200 \\
\hline & Medium & 20 & 20.620 & 1.447 & 7.017 & 103.100 \\
\hline & High & 30 & 31.794 & 0.272 & 0.855 & 105.980 \\
\hline
\end{tabular}

were processed, analyzed and compared with nominal concentrations. The stability of QC samples was also studied after three freeze and thaw cycles. Three aliquots of unprocessed QC samples were stored at $-80 \pm 2{ }^{\circ} \mathrm{C}$ and subjected to three freeze and thaw cycles. After the completion of the third cycle, the samples were processed, analyzed and the results were compared with nominal values and the results represented in Tables III and IV.

\section{Pharmacokinetic analysis}

Non-compartmental pharmacokinetic analyses were performed using Excel (Microsoft, Redmond, WA, USA) add-in program, PK solver. The estimated parameters included area under the plasma concentration-time curve $\left(A U C_{0-t}\right)$, area under the plasma time-concentration curve from time zero to infinity $\left(A U C_{0-\infty}\right)$, maximum plasma concentration $\left(C_{\max }\right)$ and time to maximum plasma

TABLE III - The results of short, long and freeze and thaw Stability of paracetamol in rat plasma

\begin{tabular}{lcccccc}
\hline Stability & QC Samples & $\begin{array}{c}\text { Concentration of } \\
\text { PAR }(\boldsymbol{\mu g} / \mathbf{m L}) \\
\text { in rat plasma }\end{array}$ & $\begin{array}{c}\text { Mean Found } \\
\text { Concentration } \\
(\boldsymbol{\mu g} / \mathbf{m L}) \text { of PAR }\end{array}$ & \pm SD & CV & Recovery\% \\
\hline Short Term & Low & 1.5 & 1.512 & 0.019 & 1.257 & 100.800 \\
Stability & High & 30 & 28.793 & 0.738 & 2.563 & 95.977 \\
\hline \multirow{2}{*}{ Long Ter Stability } & Low & 1.5 & 1.437 & 0.085 & 5.915 & 95.800 \\
& High & 30 & 28.832 & 1.897 & 6.579 & 96.107 \\
\hline Freeze \& Thaw & Low & 1.5 & 1.533 & 0.080 & 5.219 & 102.200 \\
stability & High & 30 & 30.083 & 2.367 & 7.868 & 100.277 \\
\hline
\end{tabular}

TABLE IV - The results of short, long and freeze and thaw Stability of chlorzoxazone in rat plasma

\begin{tabular}{lcccccc}
\hline Stability & QC Samples & $\begin{array}{c}\text { Concentration of } \\
\mathbf{C Z X}(\boldsymbol{\mu g} / \mathbf{m L}) \\
\text { in plasma }\end{array}$ & $\begin{array}{c}\text { Mean found } \\
\text { Concentration } \\
\text { of } \mathbf{C Z X}(\boldsymbol{\mu g} / \mathbf{m L}) \\
\text { in plasma }\end{array}$ & \pm SD & CV & Recovery\% \\
\hline Short term & Low & 1.5 & 1.553 & 0.139 & 8.950 & 103.533 \\
Stability & High & 30 & 29.251 & 0.700 & 2.400 & 97.503 \\
\hline Long term & Low & 1.5 & 1.610 & 0.034 & 2.112 & 107.533 \\
stability & High & 30 & 29.354 & 0.462 & 1.574 & 97.847 \\
\hline Freeze \& Thaw & Low & 1.5 & 1.566 & 0.138 & 8.812 & 104.400 \\
Stability & High & 30 & 30.091 & 0.364 & 1.209 & 100.303 \\
\hline
\end{tabular}


concentration $\left(T_{\max }\right)$, volume of distribution $\left(V_{d}\right)$, clearance $(c L)$ and the elimination half-life $\left(t_{1 / 2}\right)$ of both PAR and CZX, Figures 4 and 5 represent the chromatograms of the drugs in rat plasma after IV administration.

The plasma concentration-time curves after IV administration at PAR $(25 \mathrm{mg} / \mathrm{kg})$ and CZX $(20 \mathrm{mg} / \mathrm{kg})$ with either control or lycopene pretreatment $(20 \mathrm{mg} / \mathrm{kg}$, ip) are shown in Figure 6.

The pharmacokinetic parameters of PAR and CZX indicated that pretreatment of rats with Lycopene at daily dosage of $20 \mathrm{mg} / \mathrm{kg}$ for eight consecutive days resulted in a $(20.374 \% \& 45.997 \%, \mathrm{P}<0.05)$ reduction in the total clearance $(\mathrm{cL})$, respectively, compared with the control group. Nevertheless, the difference in volume of distribution $\left(\mathrm{V}_{\mathrm{d}}\right)$ was not significant between the two groups of CZX, where there was a significant increase (1.694 fold) in $V d$ of PAR compared to the control group.

The difference in $\mathrm{C}_{\max }$ and $\mathrm{T}_{\max }$ did not reach statistical significance in both PAR and CZX, but the $A U C_{0-t}, A U C_{0-\text { inf. }}, 1 / 2$ were significantly increased by 1.245,1.295 and 2.09 folds in PAR and 1.631, 1.914 and 2.216 folds in CZX $(\mathrm{P}<0.05)$, respectively, following pretreatment with Lycopene $(\mathrm{P}<0.05)$.

\section{Statistical analysis}

The different parameters (AUC, $C_{\max }, T_{\max }, V_{d}, c L$ and $t_{1 / 2}$ ) of both PAR and CZX between control group

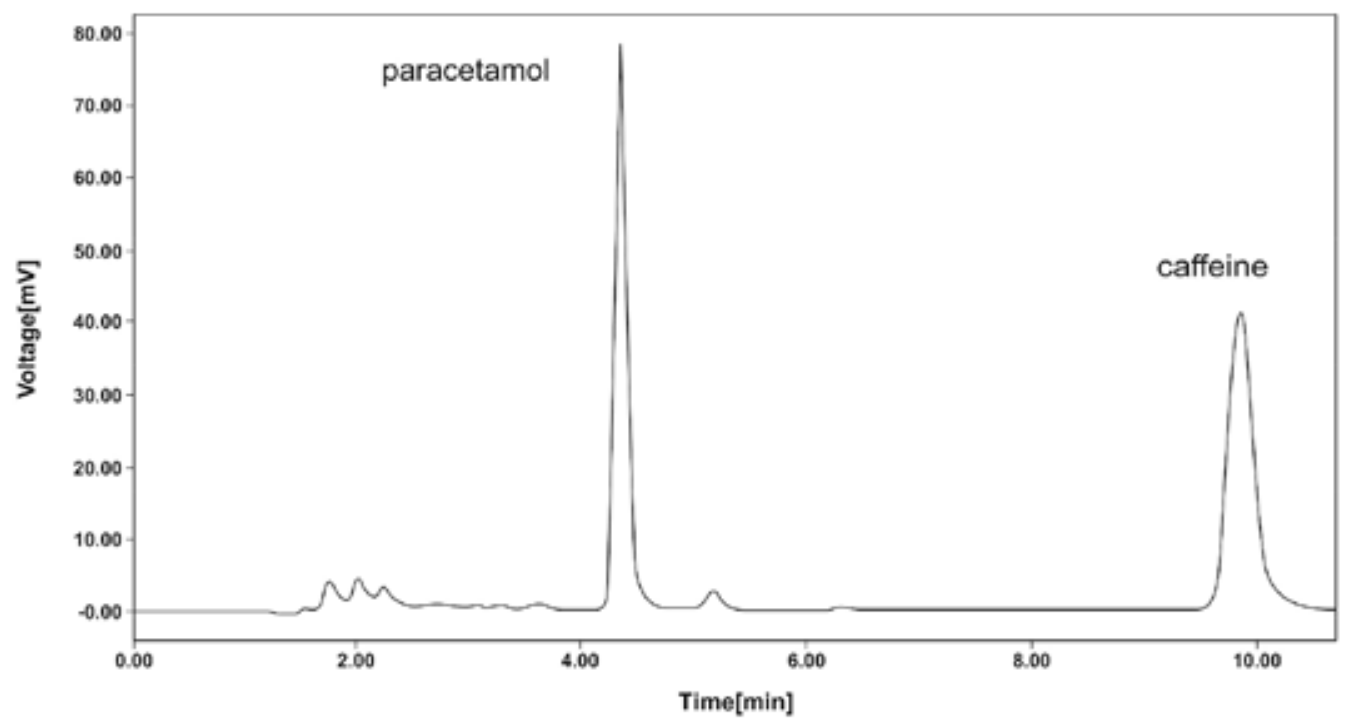

FIGURE 4 - Chromatogram of paracetamol in plasma taken from a rat after IV administration and spiked with caffeine $(80 \mu \mathrm{g} / \mathrm{mL})$.

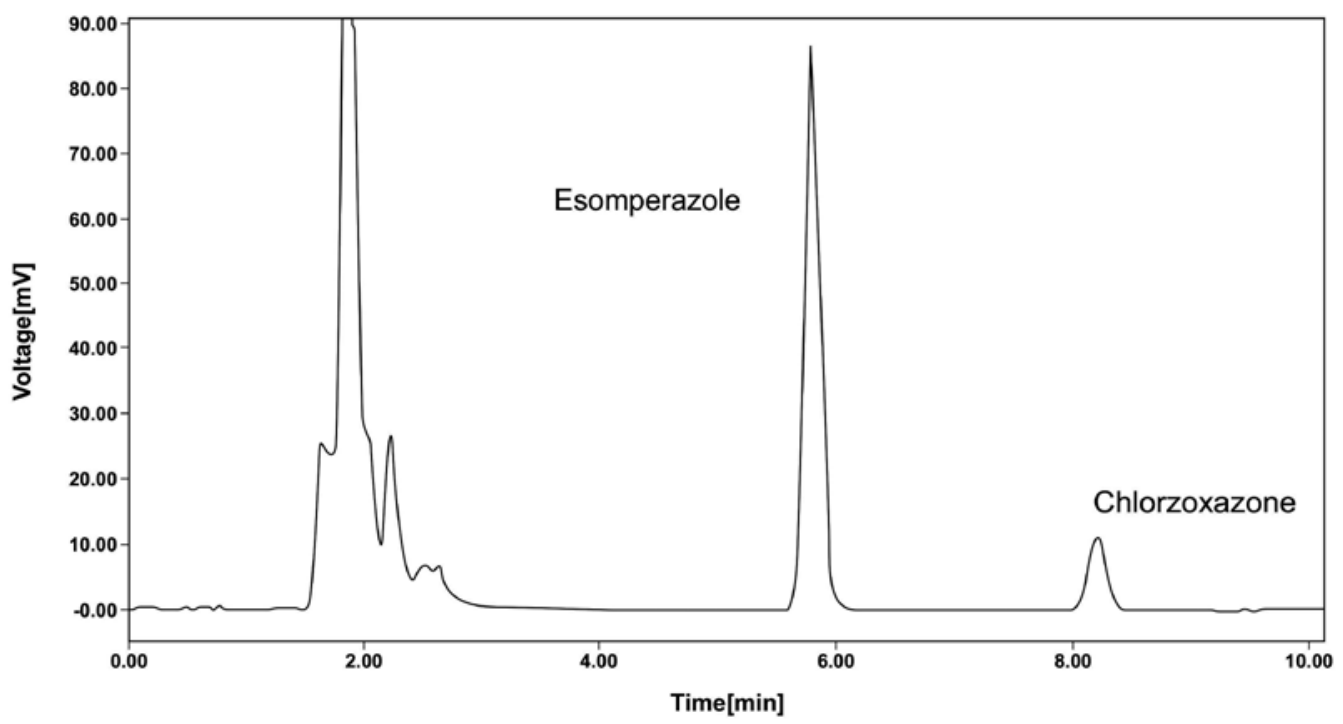

FIGURE 5 - Chromatogram of chlorzoxazone in plasma taken from a rat after IV administration and spiked with esomeprazole $(44 \mu \mathrm{g} / \mathrm{mL})$. 

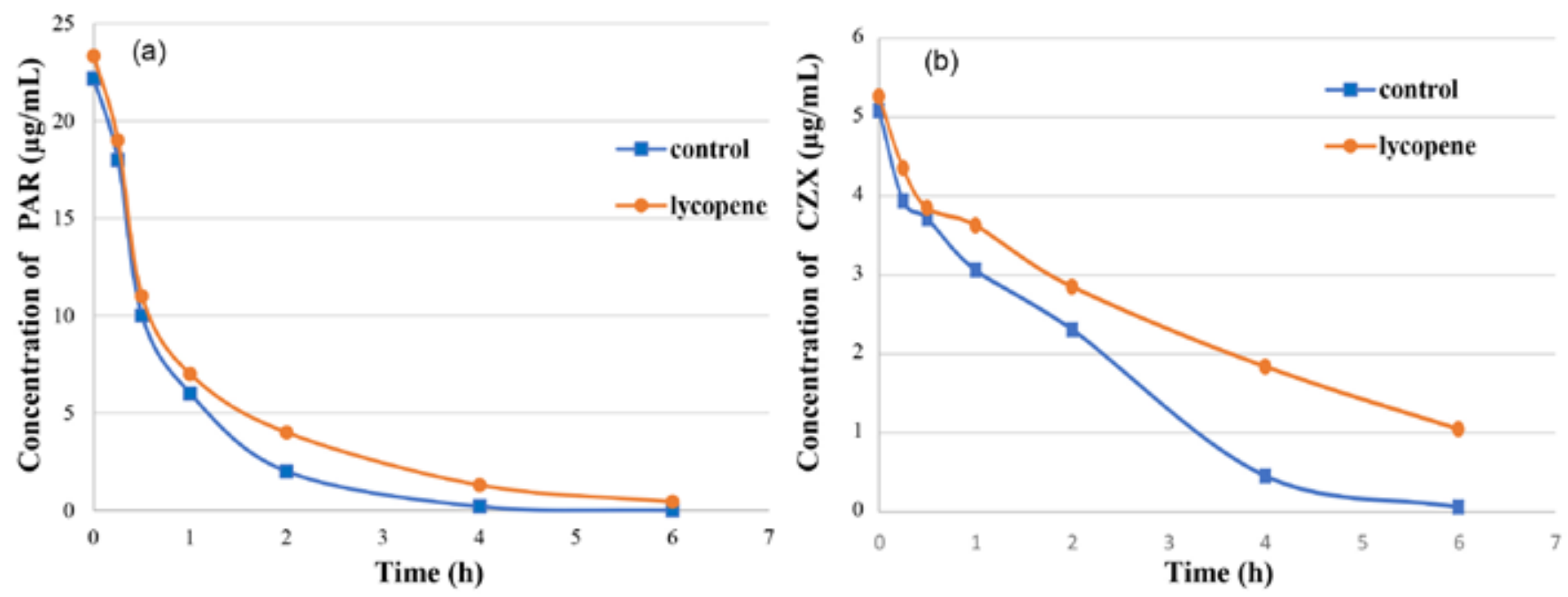

FIGURE 6 - (a) The concentration-time profile of paracetamol ( $25 \mathrm{mg} / \mathrm{kg}$, IV) after treatment with water (control) or lycopene $(20 \mathrm{mg} / \mathrm{kg}$, ip) in rats (b) The concentration-time profile of chlorzoxazone $(20 \mathrm{mg} / \mathrm{kg}$, IV) after treatment with saline (control) or lycopene $(20 \mathrm{mg} / \mathrm{kg}$, ip) in rats.

and lycopene group were compared. All statistics were calculated using IBM SPSS Statistics, Version 22, Copyright IBM Corporation and others 1989, 2013. The significance of difference between groups was analyzed by student's t-test. Differences were considered significant when $\mathrm{P}<0.05$. The results are represented in Tables $\mathrm{V}$ and VI.

TABLE V - Statistical analysis of the results obtained by comparing the control group and lycopene group for the determination of pharmacokinetics parameters of paracetamol $(25 \mathrm{mg} / \mathrm{kg})$ using student's t-test

\begin{tabular}{lccc}
\hline Parameter & Lycopene & Control & P $_{\text {cal }}$ \\
\hline $\mathrm{C}_{\text {max }}(\mu \mathrm{g} / \mathrm{mL})$ & $23.044 \pm 2.254$ & $23.224 \pm 3.032$ & 0.905 \\
$\mathrm{t}_{1 / 2}(\mathrm{~h})^{*}$ & $1.327 \pm 0.355$ & $0.635 \pm 0.118$ & 0.001 \\
$\mathrm{~V}_{\mathrm{d}}(\mathrm{mg} / \mathrm{kg}) /(\mu \mathrm{g} / \mathrm{mL})^{*}$ & $1.936 \pm 0.701$ & $1.143 \pm 0.242$ & 0.026 \\
$\mathrm{cL}(\mathrm{mg} / \mathrm{kg}) /(\mu \mathrm{g} / \mathrm{mL}) / \mathrm{h}^{*}$ & $1.0001 \pm 0.141$ & $1.256 \pm 0.178$ & 0.020 \\
$\mathrm{AUC}_{0-\mathrm{t}}(\mu \mathrm{g} / \mathrm{mL} * \mathrm{~h})^{*}$ & $24.62 \pm 3.032$ & $19.773 \pm 3.227$ & 0.038 \\
$\mathrm{AUC}_{0 \text {-inf }}\left(\mu \mathrm{g} / \mathrm{mL}^{*} \mathrm{~h}\right)^{*}$ & $26.102 \pm 3.720$ & $20.150 \pm 3.023$ & 0.015 \\
\hline
\end{tabular}

* Significant difference between two groups

TABLE VI - Statistical analysis of the results obtained by comparing the control group and lycopene group for the determination of pharmacokinetics parameters of chlorozoxazone $(20 \mathrm{mg} / \mathrm{kg})$ using student's t-test

\begin{tabular}{lccc}
\hline Parameter & Lycopene & Control & P $_{\text {cal }}$ \\
\hline $\mathrm{C}_{\text {max }}(\mu \mathrm{g} / \mathrm{mL})$ & $5.264 \pm 0.725$ & $5.298 \pm 0.424$ & .9230 \\
$\mathrm{t}_{1 / 2}(\mathrm{~h})^{*}$ & $2.988 \pm 1.0498$ & $1.348 \pm 0.112$ & .0030 \\
$\mathrm{~V}_{\mathrm{d}}(\mathrm{mg} / \mathrm{kg}) /(\mu \mathrm{g} / \mathrm{mL})$ & $4.260 \pm 0.725$ & $3.834 \pm 0.926$ & .3460 \\
$\mathrm{cL}(\mathrm{mg} / \mathrm{kg}) /(\mu \mathrm{g} / \mathrm{mL}) / \mathrm{h}^{*}$ & $1.059 \pm 0.256$ & $1.961 \pm 0.352$ & 0.000 \\
$\mathrm{AUC}_{0-\mathrm{t}}(\mu \mathrm{g} / \mathrm{mL} * \mathrm{~h})^{*}$ & $14.915 \pm 1.519$ & $9.143 \pm 2.360$ & 0.001 \\
$\mathrm{AUC}_{0-\text {-inf }}(\mu \mathrm{g} / \mathrm{mL} * \mathrm{~h})^{*}$ & $20.020 \pm 5.758$ & $10.460 \pm 1.749$ & .0030 \\
\hline
\end{tabular}

* Significant difference between two groups 


\section{DISCUSSION}

To determine the affecting dose of lycopene, many preliminary trials were carried out. Lycopene $(10 \mathrm{mg} / \mathrm{kg})$ was given IP to rats for six consecutive days followed by IV administration of PAR $(25 \mathrm{mg} / \mathrm{kg})$ or CZX $(20 \mathrm{mg} / \mathrm{kg})$. Blood samples were collected from each group at different time intervals $(0-6 \mathrm{~h})$. The results of this experiment were compared to that carried out using lycopene $(20 \mathrm{mg} / \mathrm{kg})$. Control group was carried out for each drug by pretreating with the vehicle instead of lycopene. Both experiments showed an increase in $A U C_{0-p} A U C_{0-\text {-inf }}$ and a decrease in $\mathrm{cL}$ of both PAR and CZX when pretreated with lycopene but this effect was more significant in the rats pretreated with $(20 \mathrm{mg} / \mathrm{kg})$ IP lycopene dose.

This experiment was repeated but with pretreating the rats with lycopene $20 \mathrm{mg} / \mathrm{kg}$ for eight consecutive days instead of six then PAR or CZX was IV administered. This showed that the effect of lycopene was more significant when the duration of lycopene administration was increased.

A herbal or food drug interaction occurs when a particular food alters an enzyme activity leading to changes in drug metabolism by this enzyme (Saxena et al., 2008; Schmidt, Dalhoff, 2002).

Recent study showed the inhibitory effect of tomato juice on the metabolism of some substrates of CYP3A4 such as nifedipine, testosterone and midazolam due to the inhibitor effect of lycopene and other flavonoids on CYP3A4 (Sunaga et al., 2012). But this work showed the inhibitory effect of lycopene on pharmacokinetic of paracetamol and chlorzoxazone, which is mainly metabolized by CYP2E, due to the inhibitory effect of lycopene on CYP2E1.

There are three main metabolic pathways for PAR leading to the formation of toxic or non-toxic products and eventually excreted in urine (Veronese, McLean, 1991). In the third pathway, however, the intermediate product $N$-acetyl- $p$-benzoquinone imine (NAPQI) is toxic. NAPQI is primarily responsible for the toxic effects of PAR. Production of NAPQI is due primarily to two cytochrome P450 enzymes: CYP2E1 and CYP3A4 (Foye, Lemke, Williams, 2008).

On the other hand, CZX is metabolized to OH-CZX by the hepatic microsomal cytochrome P450: CYP2E1 in humans (Lucas et al., 1995) and rats (Rockich, Blouin, 1999).

According to experimental results, it can be deduced that pretreatment of rats with lycopene in a dose of 20 $\mathrm{mg} / \mathrm{kg}$ lead to an increase in the AUC and a decrease in $\mathrm{cL}$ of both PAR and CZX and this could be a result of inhibiting CYP2E1. Because both PAR and CZX have low to intermediate hepatic extraction ratio ((Coleman, 2006; Mehvar, Vuppugalla, 2006), therefore, their hepatic clearance depends mainly on the intrinsic clearance $\left(c L_{\text {in }}\right)$ ((Bryant, Knights, 2014; Davies, Morris, 1993; Lin, Lu, 1997). So, according to equation (1), AUC increases when clearance (or intrinsic clearance in case of low clearance drugs) decreases (Lin, Lu, 1997):

$$
A U C_{\text {total }}=\operatorname{dose} / c L=\operatorname{dose} / f_{P .} C l_{\text {int }}
$$

When the rats were pretreated with Lycopene, the intrinsic and hepatic clearances decreased and $A U C_{0-\nu}$ $A U C_{0-\text {-inf }}$ of both PAR and CZX increased, whereas Lycopene had no significant effect on $C_{\max }$ as both were administered intravenously.

The elimination half-life $t 1 / 2$ increased when the volume of distribution increased, and the total clearance decreased (Lin, $\mathrm{Lu}, 1997$ ) as shown in Equation (2), and this was consistent with the experimental results that showed an increase of the elimination half-life of both PAR and CZX more than 2 folds:

$$
t_{1 / 2}=0.693 \times \mathrm{Vd} / \mathrm{Cl}
$$

Using FDA rodent-human dose conversion based on $60 \mathrm{~kg}$ average human weight (Nair, Jacob, 2016), should consume $193 \mathrm{mg}$ of lycopene per day $(20 * 60 / 6.2$ $=193 \mathrm{mg}$ ) to show the difference of the pharmacokinetic parameters for the studied drugs. 6.2 is the ratio that compares the body surface area of rats with humans.

\section{CONCLUSION}

In conclusion, the pharmacokinetic behavior of paracetamol and chlorzoxazone was remarkably changed in rats after intra-peritoneal administration of lycopene $(20 \mathrm{mg} / \mathrm{kg})$, and thus a human being should consume 193 $\mathrm{mg}$ of lycopene to show the difference of pharmacokinetic parameters for the studied drugs. Hence, it could be presumed that the increase of AUC and the decrease of cL might be due to the inhibitory effect of lycopene on CYP2E1, the main enzyme in the metabolism of paracetamol and chlorzoxazone. The results of our research might contribute to guide future clinical studies.

\section{NOTES}

The authors declare no competing conflict of interest and no financial contributions were received. 


\section{REFERENCES}

Bryant BJ, Knights KM Pharmacology for health professionals. $4^{\text {th }}$ ed. Chatswood: Elsevier; 2014.

Coleman MD. Human drug metabolism: an introduction. Chichester: John Wiley; 2006. p.i-xii.

Davies B, Morris T. Physiological parameters in laboratory animals and humans. Pharm Res. 1993;10(7):1093-5.

EMA. Guideline on bioanalytical method validation. London: EMEA, 2015. 23p. (EMEA/CHMP/EWP/192217/2009). 2011. [cited 2012 Nov 3]. Available from: h ttp://www.ema.europa.eu/ docs/en_GB/document_library/Scientific_guideline/2011/08/ WC500109686.pdf.

Foye WO, Lemke TL, Williams DA. Foye's principles of medicinal chemistry. Lippincott: Williams \& Wilkins; 2008.

Gerster H. The potential role of lycopene for human health. J Am Coll Nutr. 1997;16(2):109-26.

Kar A. Medicinal chemistry. $6^{\text {th }}$.ed. New Delhi: New Age International; 2005.

Kramer I, Dalhoff K, Clemmesen JO, Loft S, Poulsen HE. Comparison of chlorzoxazone one-sample methods to estimate CYP2E1 activity in humans. Eur J Clin Pharmacol. 2003;59(10):775-8.

Lin JH, Lu AY. Role of pharmacokinetics and metabolism in drug discovery and development. Pharmacol Rev. 1997;49(4):403-49.

Louisa M, Suyatna FD, Setiawati A, Jusman SWA. The effect of lycopene on the total cytochrome P450, CYP1A2 and CYP2E1. Med J Indones. 2009;18(4):233-8.

Lucas D, Ménez C, Girre C, Berthou F, Bodénez P, Joannet I, et al. Cytochrome P450 2E1 genotype and chlorzoxazone metabolism in healthy and alcoholic Caucasian subjects. Pharmacogenetics. 1995;5(5):298-304.

MacKinnon ES, Rao AV, Josse RG, Rao LG. Supplementation with the antioxidant lycopene significantly decreases oxidative stress parameters and the bone resorption marker $\mathrm{N}$-telopeptide of type i collagen in postmenopausal women. Osteoporos Int. 2011;22(4):1091-101.
McGill MR, Jaeschke H. Metabolism and disposition of acetaminophen: recent advances in relation to hepatotoxicity and diagnosis. Pharm Res. 2013;30(9):2174-87.

Mehvar R, Vuppugalla R. Hepatic disposition of the cytochrome P450 2E1 marker chlorzoxazone and its hydroxylated metabolite in isolated perfused rat livers. J Pharm Sci. 2006;95(7):1414-24.

Nair A, Jacob S. A simple practice guide for dose conversion between animals and human. J Basic Clin Pharm. 2016;7(2):2731.

Peter R, Böcker R, Beaune PH, Iwasaki M, Guengerich FP, Yang CS. Hydroxylation of chlorzoxazone as a specific probe for human liver cytochrome P-450IIE1. Chem Res Toxicol. 1990;3(6):566-73.

Portolés A, Puerro M, Terleira A, Rodríguez A, Caturla M-C, Fernández N, et al. A new high-absorption-rate Paracetamol 500-mg formulation: a comparative bioavailability study in healthy volunteers. Curr Ther Res Clin Exp. 2003;64(7):401-11.

Rao AV, Agarwal S. Role of lycopene as antioxidant carotenoid in the prevention of chronic diseases: a review. Nutr Res. 1999;19(2):305-23.

Rockich K, Blouin R. Effect of the acute-phase response on the pharmacokinetics of chlorzoxazone and cytochrome P-450 2E1 in vitro activity in rats. Drug Metab Dispos. 1999;27(9):1074-7.

Saxena A, Tripathi KP, Roy S, Khan F, Sharma A. Pharmacovigilance: effects of herbal components on human drugs interactions involving cytochrome P450. Bioinformation. 2008;3(5):198-204.

Schmidt LE, Dalhoff K. Food-drug interactions. Drugs. 2002;62(10):1481-502.

Schulzová V, Hajšlová J. Biologically active compounds in tomatoes from various fertilisation systems. In: $3^{\text {rd }}$. QLIF Congress. Hohenheim, 2007.

Sunaga K, Ohkawa K, Nakamura K, Ohkubo A, Harada S, Tsuda T. Mechanism-based inhibition of recombinant human cytochrome P450 3A4 by tomato juice extract. Biol Pharm Bull. 2012;35(3):329-34.

Veronese ME, McLean S. Metabolism of paracetamol and phenacetin in relation to debrisoquine oxidation phenotype. Eur J Clin Pharmacol. 1991;40(6):547-52. 
Wang G, Zhu J, Wu W, Zhang W. Simple and rapid determination of paracetamol in oral pharmaceutical preparations by a homeuse glucometer for paediatric subministration. Curr Pharm Anal. 2018;14(4):355-9.
Zand R, Nelson SD, Slattery JT, Thummel KE, Kalhorn TF, Adams SP, et al. Inhibition and induction of cytochrome P4502E1-catalyzed oxidation by isoniazid in humans. Clin Pharmacol Ther. 1993;54(2):142-9.

Received for publication on $07^{\text {th }}$ February 2018 Accepted for publication on $16^{\text {th }}$ May 2018 